\title{
STATCOM Evaluation in Electrified Railway Using V/V and Scott Power Transformers
}

\author{
Luis A. M. Barros ${ }^{1}$, Mohamed Tanta ${ }^{1}$, António P. Martins ${ }^{2}$, João L. Afonso ${ }^{1}$, \\ J. G. Pinto ${ }^{1}$ \\ ${ }^{1}$ Centro ALGORITMI - University of Minho, Guimarães - Portugal \\ ${ }^{2}$ SYSTEC Research Center - University of Porto, Porto - Portugal \\ lbarrosedei.uminho.pt
}

\begin{abstract}
Rail transport has always been one of the greatest economic boosters of several world nations, allowing the freight and passenger transport. In addition, it is the most secure and economic land transportation mode. From the energetic perspective, the electric locomotives emerge as one of the most efficient land transportation mode, as well as allow a more sustainable development. However, when an electric locomotive is connected to the three-phase power grid, power quality (PQ) deterioration arise, leading to the distortion and unbalance of the three-phase power grid currents and voltages which imply higher operational costs, raising economic and functional issues. In order to overcome the PQ deterioration phenomena, several solutions based power electronics technology have been studied and developed. These solutions vary in terms of control, functionality, implementation costs and complexity. One of the existing solutions is a static synchronous compensator (STATCOM), which compensates the three-phase currents imbalance and harmonics.

In this paper, a comprehensive review of the electrified railway systems is carried out, identifying the electric PQ phenomena which may appear due to the non-linear dynamic traction loads. Following this topic, a computational simulation of the STATCOM is presented, making analysis of its behavior regarding the PQ improvement in electrified railway systems. Two case studies are presented: (i) a traction power system fed with $\mathrm{V} / \mathrm{V}$ power transformer; (ii) a traction power system fed with Scott power transformer.
\end{abstract}

Keywords: Scott Power Transformer, STATCOM, V/V Power Transformer.

\section{Nomenclature}

$$
\begin{aligned}
& i_{\text {Comp_A }}, \quad \text { Instantaneous current compensation value synthesized by STATCOM } \\
& i_{C o m p \_B}, \quad \text { in phase } A, \text { phase } B \text { and phase } C, \text { respectively } \\
& i_{\text {Comp_C }}
\end{aligned}
$$




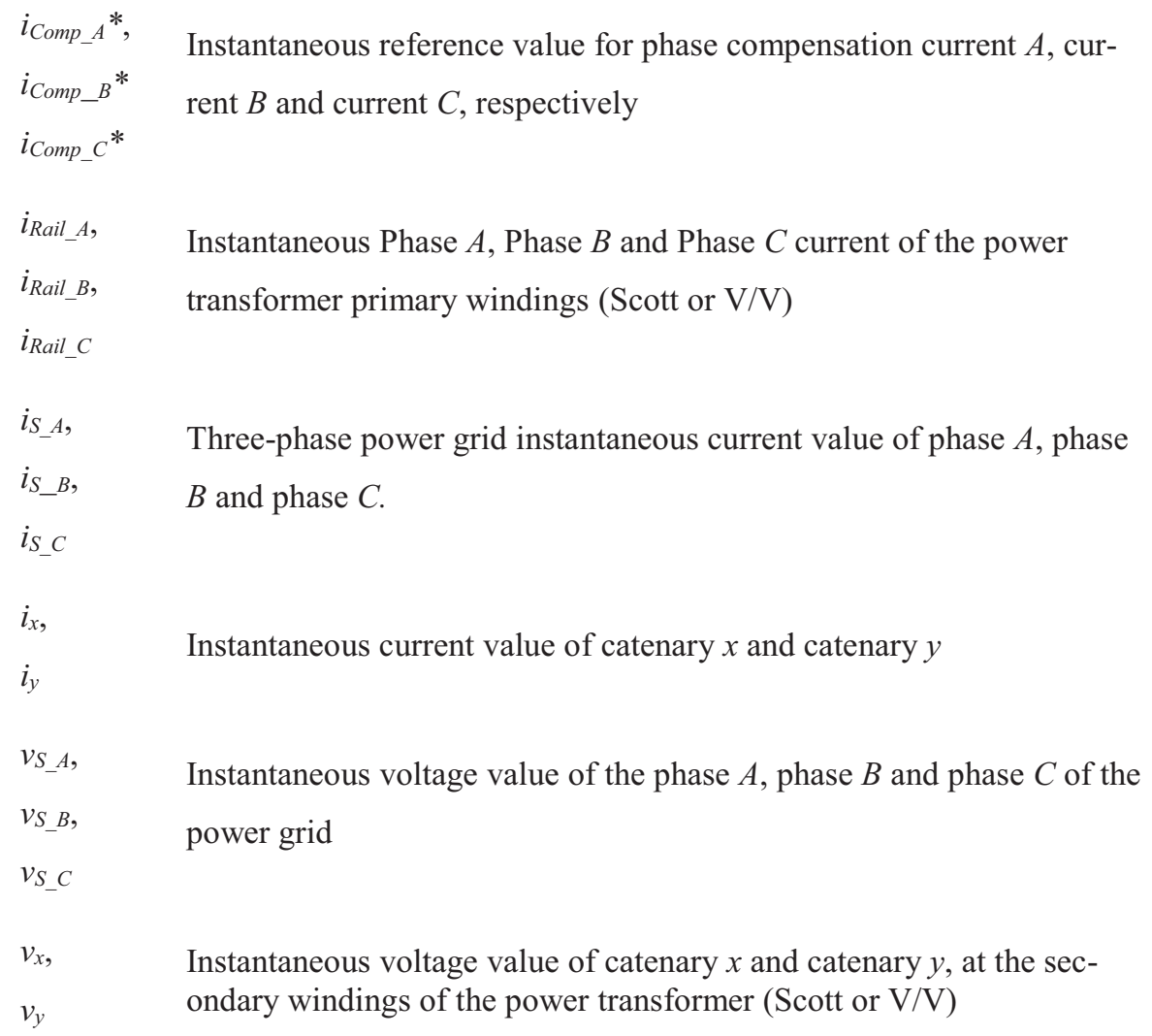

\section{Introduction}

Rail transport is seen as the safer and more economical comparing to other land transportation modes. In addition, it is recognized as one of the main catalysts for the economic growth of nations. For instance, in the European case, railway transportation mode made more than 26.9 billion (26 900000000 ) individual trips in 2012, providing employment to 2.3 million people, reflecting a gross value of 143 billion Euros, more than air and sea transport [1]-[3]. Despite the strong impact of the rail transport mode on the industrial revolution in the early $18^{\text {th }}$ century, electrification of the railway lines had only occurred almost seventy years later.

In order to cover the railway transport demand, several incentive programs for the technological development of the electric rail system have been created and expanded, such as the AVE (Alta Velocidad Espanhola) train in Spain, FRECC (Frecciarossa Trains) in Italy, ICE (InterCity Express) in Germany and TGV (Train à Grande Vitesse) in France. These programs allowed a rail growth of 17\% from 2001 to 2012 in Europe. However, the continuous proliferation of electric locomotives caused a significant power quality (PQ) deterioration in the three-phase electrical power grid. 
Nowadays, PQ improvement in the three-phase power grid is one of the major concerns for scholars. The problems of $\mathrm{PQ}$ affect not only the costs, but also the functionality of some electronic equipment that are sensitive to power perturbation (e.g., medical and database equipment). In 2006 the Leonard Power Quality Initiative presented a study of PQ impact on the European industry, claiming that this type of problem caused losses of over $€ 150$ billion [4]. Fig. 1 presents some of PQ deterioration phenomena existing in the three-phase power grid, highlighting the electric railway system.

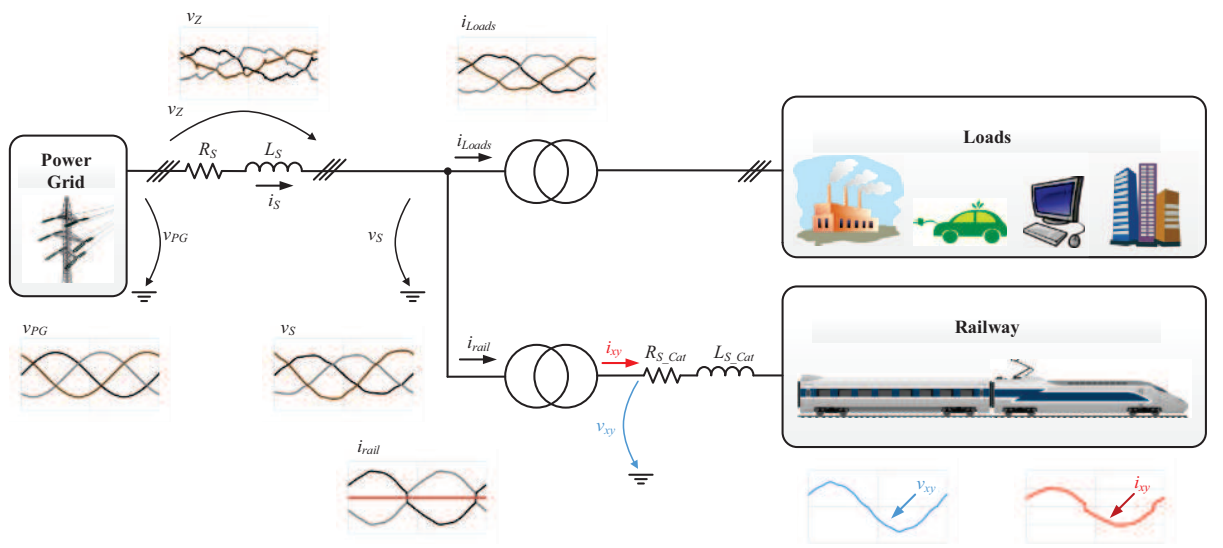

Fig. 1. Example of some PQ deterioration phenomena in the three-phase power grid.

Historically, electric railway presents a complex system capable of consuming enormous amount of energy. On the other hand, PQ phenomena could have a more severe impact when several electric locomotives are fed by the same catenary overhead line. Thus, from the electrical point of view, it is necessary to first understand the equivalent electric model of the locomotive as presented in [5] and in Fig. 3. When an electric locomotive is connected into the catenary, different power quality phenomena arise, namely: system unbalance, harmonics, non-unitary power factor and transients. Some of these phenomena are represented in Fig. 2.

Voltage unbalance represented in Fig. 2 (a), is the most problematic issue of the electric railway system. Considering the electric locomotives are single-phase loads, they cause currents and voltage unbalance in the three-phase power grid, injecting currents with Negative Sequence Components (NSCs) [6]-[8]. In this context, and considering the electric model presented in [5], a higher number of locomotives fed by the same catenary line signifies a higher power consumption and consequently, the greater the voltage drop in the power transmission lines represented in Fig. 1.

Harmonic contents represented in Fig. 2 (b), is the second most severe PQ phenomenon of electrical railway systems. The electric locomotives use AC/DC/AC power converters to adjust the electric quantities (voltage, current and/or frequency). The first stage of conversion being commonly constituted by an uncontrolled diode bridge rectifier [6]. In turn, there are already solutions that use semi-controlled semiconductors and fully-controlled semiconductors, using for this purpose thyristors, Gate-Turn-OFF (GTO), and IGBT [9]. Some phenomena associated with this system are identified in 
[6], [7]. Table 1 presents an example of harmonic components in three-phase electrical power grid, $220 \mathrm{kV}$ line-to-line in this case.

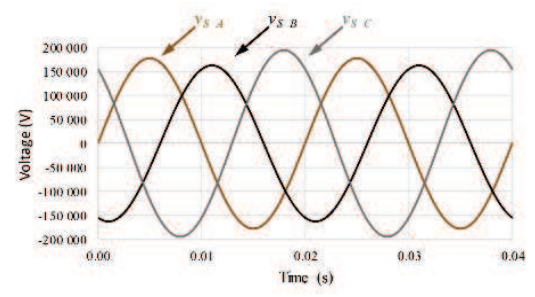

(a)

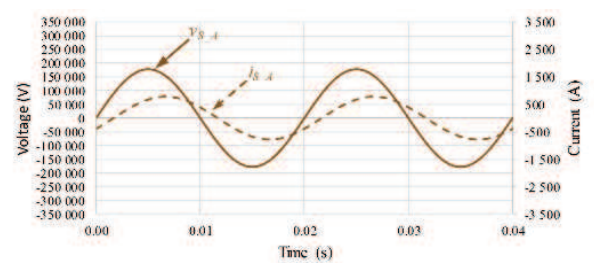

(c)

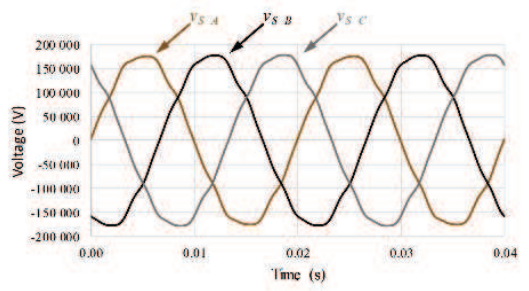

(b)

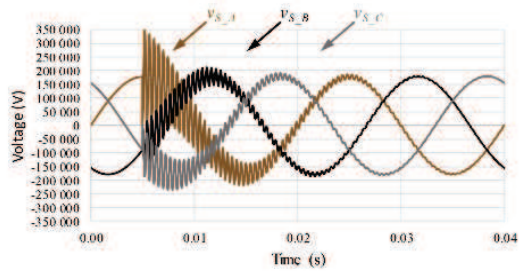

(d)

Fig. 2. Examples of power quality phenomena: (a) Voltage unbalance; (b) Voltage harmonics; (c) Low power factor; (d) Voltage transients.

A unitary value of the power factor indicates a low reactive power. In turn, the presence of high reactive power reflects a low power transmission system efficiency [7]. Despite the need for reactive power to the traction system, in the case of an inductive load, its value must be reduced to avoid higher energy losses. This ambiguity can be mitigated by the addition of Active Power Conditioners (APC) capable of locally produce the required reactive power, thus reducing the losses in the power grid and, consequently, the energy costs [6]. An example of a system with non-unitary power factor is represented in Fig. 2 (c).

The catenary height, the pantograph wear and the transition between neutral sections (NSs) are some of the intermittent operations of electric locomotive. These momentary operations may originate transients phenomena being able to damage the rail equipment [6], [10], as shown in Fig. 2 (d).

Considering the topics mentioned above, this paper presents a study of a STATCOM compensating PQ phenomena in electrified railway systems powered by V/V and Scott power transformers. In this sense, this work is structured as follows: in Section 1, an introduction to the research topic is made, presenting the problems of PQ in the power grid. Section 2 presents the existing solutions to overcome the PQ phenomena, with a higher focusing on the STATCOM topology. Section 3 presents the STATCOM simulation results in $\mathrm{V} / \mathrm{V}$ and Scott power transformers. Finally, section 4 presents the final conclusion of the work. 
Table 1. Example of harmonic components in three-phase electrical power grid $(220 \mathrm{kV}$ line-to-line voltage).

\begin{tabular}{lrrrrrr}
\hline \multirow{2}{*}{ Harmonic Order } & \multicolumn{2}{c}{ Phase A } & \multicolumn{2}{c}{ Phase B } & \multicolumn{2}{c}{ Phase C } \\
& $\left(V_{\text {RMS }}\right)$ & $\left({ }^{\circ}\right)$ & $\left(V_{\text {RMS }}\right)$ & $\left({ }^{\circ}\right)$ & $\left(V_{\text {RMS }}\right)$ & $\left(^{\circ}\right)$ \\
\hline $1^{\circ}$ & 126022 & 0 & 126739 & -120 & 126960 & -240 \\
$3^{\circ}$ & 552 & 95 & 828 & -257 & 662 & -266 \\
$5^{\circ}$ & 331 & 135 & 717.6 & -272 & 828 & -155 \\
$7^{\circ}$ & 4582 & 44 & 3974 & -77 & 3919 & -195 \\
$9^{\circ}$ & 883 & -147 & 828 & -160 & 1104 & -149 \\
$11^{\circ}$ & 2042 & -134 & 2153 & -12 & 1987 & -249 \\
$13^{\circ}$ & 110 & 29 & 110 & -292 & 276 & -226 \\
$15^{\circ}$ & 166 & -20 & 221 & -20 & 221 & -20 \\
\hline THD $\%^{\circ}$ & $2.88 \%$ & \multicolumn{6}{c}{$2.64 \%$} & $2.60 \%$ & \\
\hline
\end{tabular}

\section{Railway Power System}

In the combustion-engine locomotives, clean and noiseless solutions are required when passing through residential areas and with fewer vibrations for better passenger comfort. The electric railway system presents a viable solution that meets these requirements. In addition, there is a range of potentialities that can be explored, such as the integration of renewable energies and the energy recovering from regenerative braking. However, this system is still complex and needs to be investigated. This chapter discusses the existing solutions to overcome the PQ phenomena.

\subsection{Conventional Railway Power Systems}

Considering that electric locomotives are single-phase loads, the installation of a single-phase power transformer in a substation would locally intensify the imbalance of the system [11]. For that reason, other power supply schemes are required to reduce the PQ deterioration. One of the most basic, inexpensive and old method is to alternate phase connections of the power transformers with the three-phase power grid, being commonly referred in the literature as a phase-shift method. This method allows to reduce the NSCs and, consequently, the system imbalance [7]. For a better performance, two power transformers, in different phases, are usually installed in a given substation, and the connections in the adjacent substations are alternated.

The catenary may be supplied by electrical power grid with different amplitudes and phases, it is necessary to create NS, in order to avoid short circuits between phases of the power grid. The NS can extend from several meters up to some kilometers [6], [10], [11]. This requirement prevents the power flow of the adjacent substations, as well as causing an interrupted operation when passing through the NS, causing a power perturbation [6], [12]. Despite being a simple solution, it presents high robustness due to the overloading capability and the long-life cycle of the power transformers. However, the currents imbalance is reduced but still remaining. 
Considering the rapid growth of railway networks, it is necessary to implement solutions capable of meeting the new requirements. Thus, other configurations using three-phase power transformers are employed, namely the V/V, Scott, Le Blanc, Impedance Matching and Woodbridge power transformers [13]. An example of the integration of these first two solutions into the railway power system is shown in Fig. 3.

$\mathrm{V} / \mathrm{V}$ power transformer is the most used in railway applications due to its simple construction and the high overloading capability. The transformation ratio is given by $N 1: N 2$, which represents the relation between the three-phase power grid voltages and the catenary voltage. [13], [14]. These power transformers are dimensioned to provide all the power required by the single-phase traction loads (e.g., V/V transformer nominal power is comprised between $40 \mathrm{MVA}$ and $60 \mathrm{MVA}$ [1], [7]. On the other side, Scott power transformer is one of the emerging solutions for powering rail systems. Its versatility in balancing operating conditions on the three-phase power grid side contrasts with the complexity at construction level.

However, a dynamic compensation of these PQ phenomena is required, and the integration of APC is important in order to dynamically compensate the PQ phenomena. From this perspective, APC in conjunction with three-phase transformers present an interesting solution to overcome the power quality phenomena.

\subsection{Power Conditioners for Railway Power Systems}

With the evolution of technology in power electronics and the introduction of semiconductors, it was possible to present and implement more flexible solutions in the compensation of PQ phenomena. In this context, APCs present themselves as a very attractive solution to the requirements of the existing electrical system. Some examples of APC are the Static VAr Compensator (SVC), Static Synchronous Compensator (STATCOM), Static Frequency Converter (SFC) and Rail Power Conditioner (RPC). The functionality of the above-mentioned systems is presented with more detail in [6], [7], [10], [15]. STATCOM control algorithm is presented in [16] for the compensation of PQ phenomena. On the other hand, selective control algorithms to be implemented in RPC are presented in [5].

STATCOM will be the main contribution of this study, being shown in Fig. 3 an electric schematic of connection of the STATCOM with the railway power system. In addition, two topologies of power transformers (V/V and Scott) are considered in this study.

The STATCOM, shown in Fig. 3, takes an advantage of the technological evolution of the semiconductors, switching at higher frequencies when compared to the SVC, presenting in this way an attractive solution able to mitigate PQ phenomena related to harmonics, NSC and reactive power [7]. As can be seen, this solution is composed by a DC-bus followed by a voltage source DC-AC power converter. The STATCOM is connected between the three-phase power grid and the railway power system. In addition, the STATCOM is responsible for providing the harmonic contents required by the load, with the power grid being responsible for providing only the active power at the fundamental frequency component $(50 \mathrm{~Hz})$. However, because of the low voltage supported by the semiconductors, a power transformer is required to interface between the STATCOM and the three-phase power grid, inflating the installation cost [6], [10], [15]. 
One solution would be the STATCOM based modular and multilevel converters in order to provide the necessary voltage.

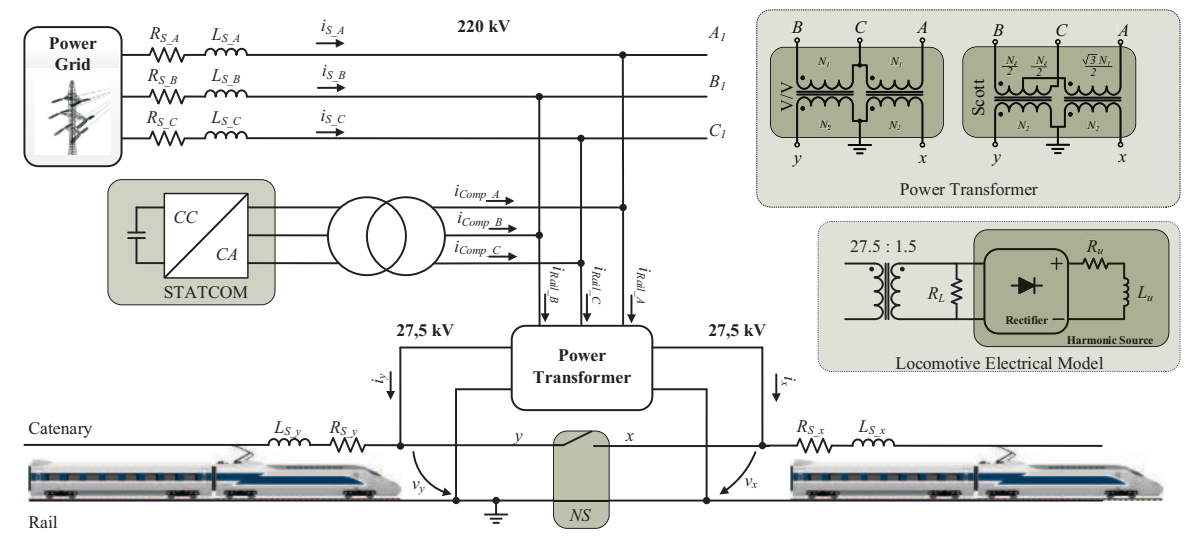

Fig. 3. Electrical schematic of the STATCOM connection with the railway power system powered by $\mathrm{V} / \mathrm{V}$ or Scott transformers.

\section{Simulation Results}

For simulation purposes a DC-AC converter with the control theory presented in [16] was implemented. The simulation results are shown in the Fig. 4 for a railway power system powered by a V/V power transformer, and the Fig. 5 shows the simulation results of the system powered by a Scott power transformer. Fig. $\mathbf{6}$ shows an analysis of the THD when a balanced load condition is introduced, with only one locomotive in each catenary.

For the following explanation, it is necessary to refer that were considered different load scenarios, as presented in Fig. 4 (a) and Fig. 5 (a). At the time instant of $0.02 \mathrm{~s}$ an electric locomotive is added in the catenary $x$, and after the time instant of $0.04 \mathrm{~s}$ the locomotive is moved to the catenary $y$. At the time instant of $0.1 \mathrm{~s}$ another locomotive is added to the catenary $x$, thus leaving a locomotive in each catenary. Finally, at the time instant of $0.16 \mathrm{~s}$ there are two locomotives in the catenary $y$ and only one in the catenary $x$, reflecting an unbalance load scenario. These load ratings over the time are reflected in current consumption $i_{x}$ and $i_{y}$, in catenary $x$ and catenary $y$, respectively. In this context:

- Fig. 4 (b) and Fig. 5 (b) represents the three-phase power grid voltages, $v_{S_{-} A}, v_{S_{-} B}$ and $v_{S_{-} C}$;

- Fig. 4 (c) and Fig. 5 (c) represents the three-phase power grid currents $i_{S_{-} A}, i_{S_{-} B}, i_{S_{-} C}$;

- Fig. 4 (d) and Fig. 5 (d) represents the currents of the power transformer primary windings $i_{\text {Rail_A }}, i_{\text {Rail_B }}, i_{\text {Rail_C}}$;

- Fig. 4 (e) and Fig. 5 (e) represents the compensation currents, $i_{C o m p \_A}, i_{C o m p \_B}, i_{C o m p} C$, synthesized by STATCOM; 
- Fig. 4 (f) and Fig. 5 (f) represents the voltage in the catenaries $x$ and $y, v_{x}$ and $v_{y}$, at the secondary windings of the power transformer;

- Fig. 5Fig. 4 (g) and Fig. 5 (g) represent the currents of catenaries $x$ and $y, i_{x}$ and $i_{y}$.

In order to evaluate the overall STATCOM performance with a V/V or a Scott power transformer, the THD ratio was calculated at the moment when catenary load sections $x$ and $y$ were equally loaded. To highline that these values, presented in Table 2., were obtained without any dynamic compensation by the STATCOM.

Table 2. THD ratio in the voltages and currents at the three-phase power grid and the railway power system, without using the STATCOM.

\begin{tabular}{ccccccccccc}
\hline & $v_{S \_A}$ & $v_{S \_B}$ & $v_{S \_} C$ & $i_{S \_A}$ & $i_{S \_B}$ & $i_{S \_C}$ & $v_{x}$ & $v_{y}$ & $i_{x}$ & $i_{y}$ \\
\hline $\mathrm{V} / \mathrm{V}$ & $4.10 \%$ & $3.76 \%$ & $3.68 \%$ & $10.6 \%$ & $10.6 \%$ & $6.64 \%$ & $3.75 \%$ & $3.58 \%$ & $10.6 \%$ & $10.6 \%$ \\
Scott & $4.07 \%$ & $3.76 \%$ & $3.67 \%$ & $12.7 \%$ & $10.5 \%$ & $11.7 \%$ & $3.83 \%$ & $3.58 \%$ & $12.7 \%$ & $10.6 \%$ \\
\hline
\end{tabular}

It is possible to verify the existence of harmonic contents in the voltages and currents, where the current waveforms contain a higher ratio of THD as presented in Table 2. In addition, almost similar THD ratios were obtained when using the V/V or the Scott power transformer. However, the main difference was in the THD of phase $C$ current $i_{S} C$. In general, V/V and Scott power transformers do not totally overcome the PQ phenomena and they cannot follow the dynamic behavior of the non-linear load. With this in mind, a dynamic compensator based on power electronics (e.g., STATCOM) is required.

\subsection{Simulation Results of the Railway System Powered by V/V Power Transformer}

In relation to the railway power system powered by $\mathrm{V} / \mathrm{V}$ power transformer, represented in Fig. 4 (b) and Fig. 4 (f), it is possible to verify that $v_{S_{-} A}, v_{-} B, v_{S_{-} C}, v_{x}$ and $v_{y}$, present harmonic contents caused by non-linear loads connected to the three-phase power grid.

At the time instant of $\mathrm{t}=0 \mathrm{~s}$, the railway system is operating without load, being possible to see that $v_{x}$ lags $v_{S_{A}}$ by $30^{\circ}$. On the other hand, $v_{y}$ is $60^{\circ}$ behind in relation to $v_{x}$, that is, it lags the $v_{S_{-} A}$ by $90^{\circ}$. In addition, it is possible to verify that $i_{S_{-} A}, i_{S_{-} B}$ and $i_{S_{-} C}$ are initially unbalanced and with high THD ratio. When the STATCOM is disabled, the currents $i_{\text {Rail_A }}, i_{\text {Rail_B }}$ and $i_{\text {Rail } C}$, are equal to the currents $i_{S_{-} A}, i_{S_{-} B}$ and $i_{S_{-} C}$. Considering this fact, when a locomotive is added in the catenary $x$, at the time instant of $\mathrm{t}=0.02 \mathrm{~s}$, can be verified the existence of $i_{x}$ with THD ratio. This phenomenon is

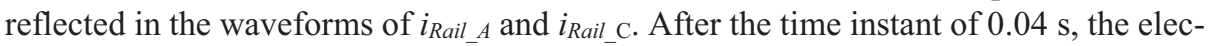
tric locomotive passes to the catenary $y$ side, replicating the simulation results obtained in the previous instant, being at this time the phase $B$ and $C$ of the three-phase power grid responsible for the power supply. Consequently, the current $i_{\text {Rail } B}$ and $i_{\text {Rail_C }}$ present high THD ratio. Additionally, in these two scenarios, it can be seen there is a three-phase high currents imbalance, when only one side of the catenary is loaded. 
(a)

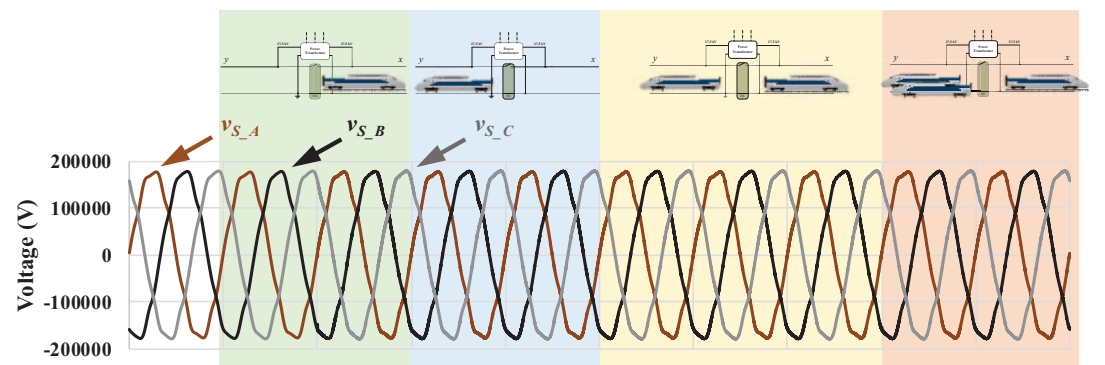

(c)

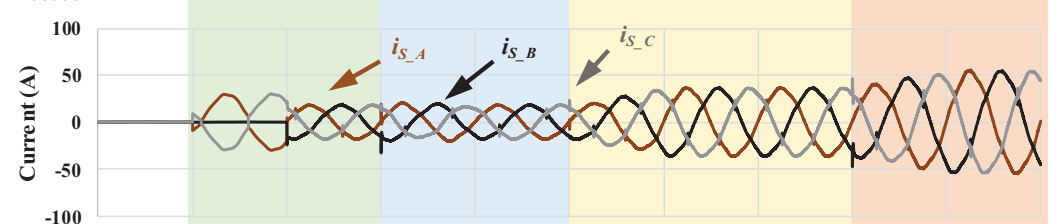

(d)

(e)
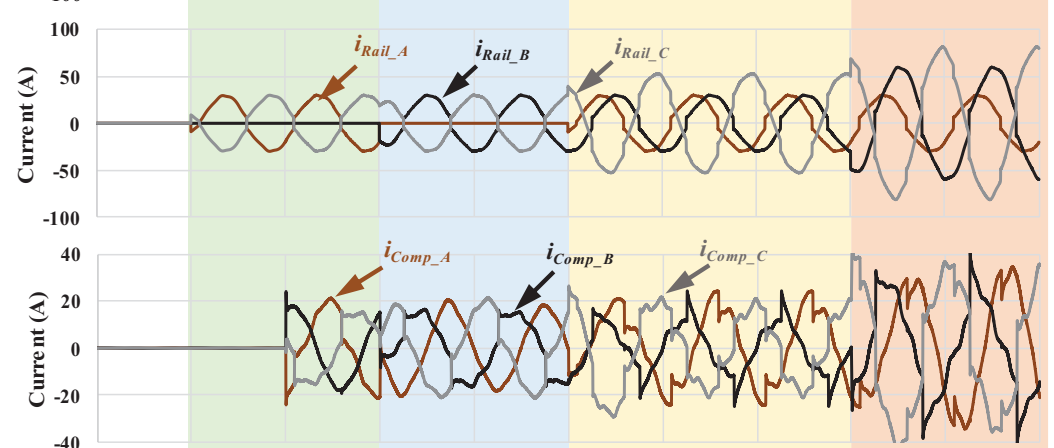

(f)

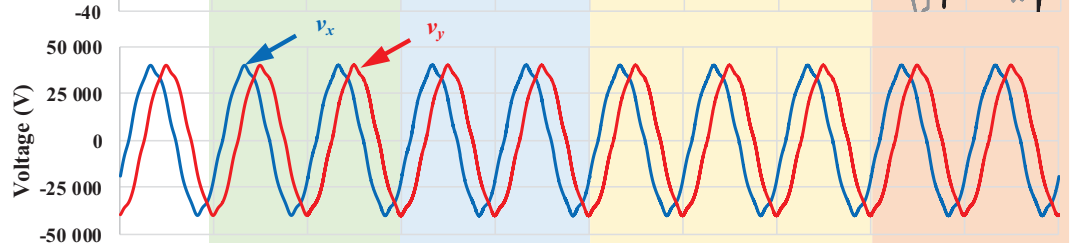

$(\mathrm{g})$

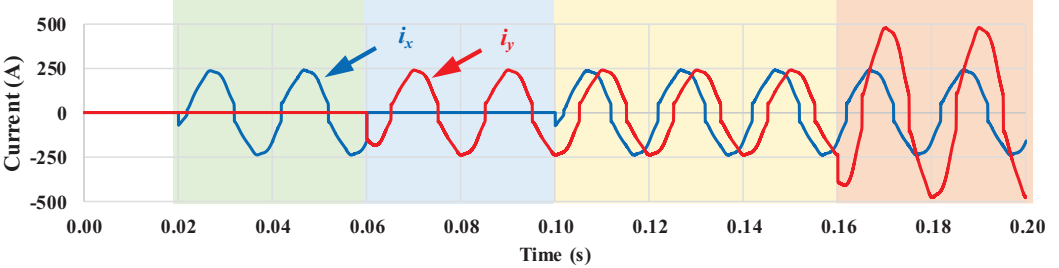

Fig. 4. Simulations results of the STATCOM compensating the power quality problems existing in the railway system powered by a V/V power transformer (a) Case scenarios with different number of locomotives in the catenaries; (b) Three-phase power grid voltages $v_{S_{-} A}, v_{S_{-} B}$ and $v_{S_{-} C}$; (c) Currents of the power grid $i_{S_{-} A}, i_{S_{-} B}, i_{S_{-} C}$; (d) currents of the railway system measured at the power grid side, $i_{\text {Rail_ }} A, i_{\text {Rail_ }} B, i_{\text {Rail_ }} C$; (e) Compensation currents, $i_{\text {Comp }} A, i_{\text {Comp }} B, i_{C o m p} C$; (f) Voltage in the catenaries, $v_{x}$ and $v_{y}$; (g) Currents of catenaries, $i_{x}$ and $i_{y}$.

At the time instant of $\mathrm{t}=0.10 \mathrm{~s}$, there are two locomotives in the railway power system, one in the catenary $x$ and the other in the catenary $y$, consuming a current $i_{x}$ and $i_{y}$, 
respectively. These two currents are in phase with the respective voltages of the catenary side $v_{x}$ and $v_{y}$. Once again, $i_{\text {Rail } A}, i_{\text {Rail }} B$ and $i_{\text {Rail } C}$ reflect the non-sinusoidal waveform of the catenary side currents, being the current $i_{\text {Rail } \_}$in phase with $i_{x}$ and $i_{\text {Rail } B}$ in phase with $i_{y}$. In addition, summing $i_{\text {Rail_A }}$ with $i_{\text {Rail_B }}$ results in $i_{\text {Rail_C }}$.

At the time instant of $\mathrm{t}=0.16 \mathrm{~s}$, a railway system powered by $\mathrm{V} / \mathrm{V}$ power transformer, another unbalance scenario was considered in the simulation, in which, catenary $x$ has one locomotive and catenary $y$ has two locomotives. At this moment, it can be verified that the waveforms of $i_{x}$ and $i_{y}$, as well as the currents $i_{\text {Rail } A}, i_{\text {Rail } B}$ and $i_{\text {Rail } C}$, are distorted. Considering the locomotives are equal and the catenary $y$ has double the load value of catenary $x$, it can be seen that $i_{y}$ has twice the amplitude of $i_{x}$. Consequently, $i_{\text {Rail } B}$ will also have twice the amplitude of $i_{\text {Rail_ } A}$. Once again, by adding these two currents, results in $\mathrm{i}_{\text {Rail } C}$, having a 2.6 times greater amplitude than $\mathrm{i}_{\text {Rail_A }}$.

At the moment that STATCOM is activated, at the time instant of $\mathrm{t}=0.04 \mathrm{~s}$, it is able to inject the harmonic contents and reactive power, required by the railway system, making $i_{S_{A} A}, i_{B}$ and $i_{S_{C}}$ sinusoidal and balanced. In fact, the railway system continues to consume a highly distorted current, $i_{\text {Rail_A }}, i_{\text {Rail_B }}$ and $i_{\text {Rail } C}$, as can be seen in Fig. 4 (d). To highlight that, the STATCOM was able to dynamically overcome the PQ deterioration, independently of the load variations. At this moment, it is important to highlight that the compensation currents synthetized by the STATCOM have an average peak value of $20 \mathrm{~A}$, reaching a twice of this when two locomotives are connected to the catenary $y$. By performing a detailed analysis of the obtained results and within the aim of calculating the harmonic distortion, it was possible to verify that the implemented system can reduce the THD of the currents $i_{S_{-} A}, i_{-} B$ and $i_{S_{-} C}$, from the values presented in Table 2., for $2.99 \%, 2.75 \%$ and $2.89 \%$ respectively. This represent an average reduction of $67 \%$ in terms of the THD.

\subsection{Simulation Results of the Railway System Powered by Scott Power Transformer}

Similarly, to the V/V power transformer, computational simulations were used to study the operation principle of the Scott power transformer with more detail.

At the time instant of $\mathrm{t}=0 \mathrm{~s}$, the railway system is operating without load, being possible to see that $v_{x}$ is in phase with $v_{s_{-} A}$. On the other hand, $v_{y}$ is $90^{\circ}$ behind in relation to $v_{x}$, that is, it lags the $v_{S_{-} A}$ by $90^{\circ}$. In addition, it is possible to verify that $i_{S_{-} A}, i_{S_{-} B}$ and $i_{S_{-} C}$ are initially unbalanced and with high THD ratio.

When the STATCOM is disabled, the currents $i_{\text {Rail } A}$, $i_{\text {Rail_B }}$ and $i_{\text {Rail_C }}$, are equal to the currents $i_{S_{-} A}, i_{S_{-} B}$ and $i_{S_{-} C}$. Considering this fact, when a locomotive is added in the catenary $x$, at the time instant of $\mathrm{t}=0.02 \mathrm{~s}$, can be verified the existence of $i_{x}$ with THD ratio. However, it should be noted that on the power grid side, and unlike the $\mathrm{V} / \mathrm{V}$ power transformer, all phases contribute to supply of the railway system. Although all the phases contribute to the feeding of the system, $i_{\text {Rail_ } A}$ is double than $i_{\text {Rail } B}$ and $i_{\text {Rail_C }}$.

After the time instant of $0.04 \mathrm{~s}$, the electric locomotive passes to the catenary $y$ side, creating a different phenomenon from the one existed in the previous instant. When only locomotives are found in the catenary $y$, the unbalance ratio is higher, existing only $i_{\text {Rail_B }}$ and $i_{\text {Rail_C. }}$. 
(a)

(b)

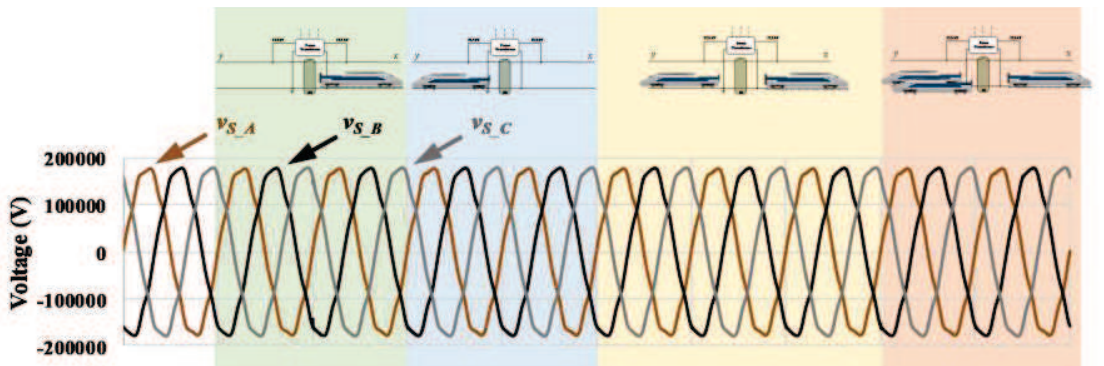

(c)

(d)

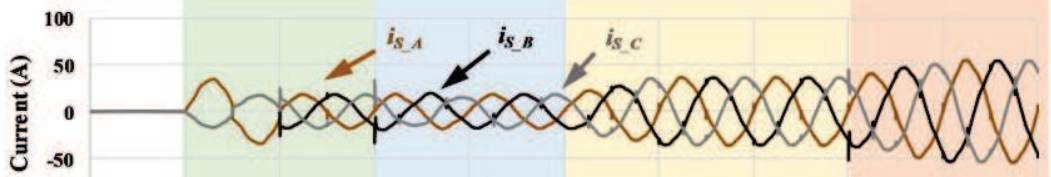

$-10$

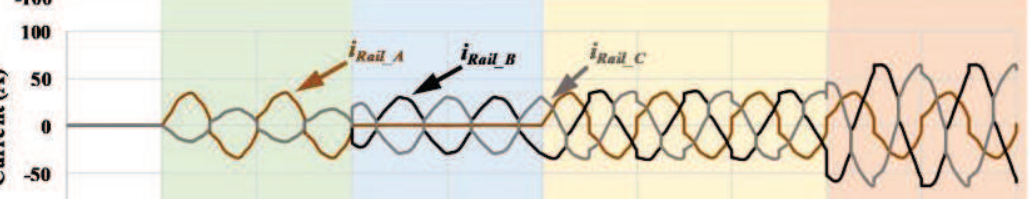

(e)

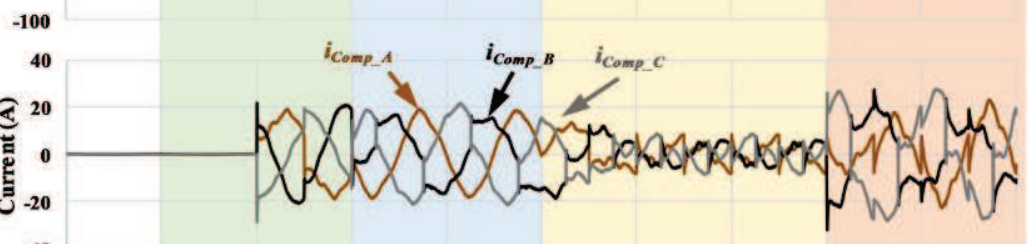

(f)

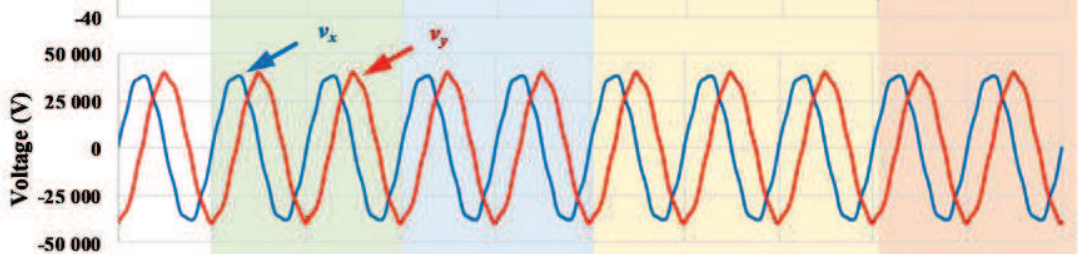

(g)

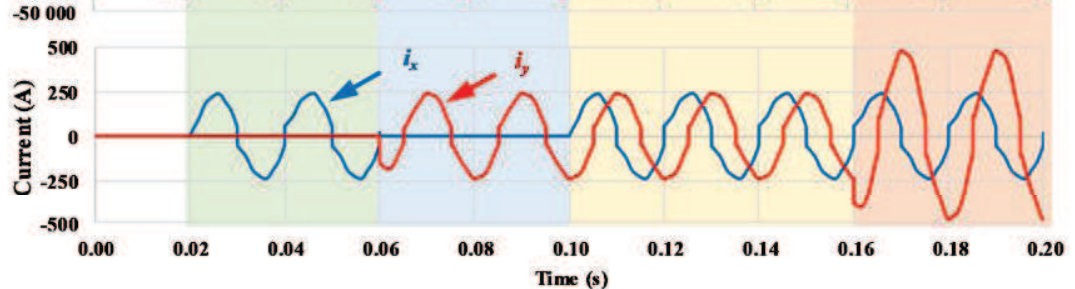

Fig. 5. Simulations results of the STATCOM compensating the power quality problems existing in the railway system powered by a Scott power transformer: (a) Case scenarios with different number of locomotives in the catenaries; (b) Three-phase power grid voltages $v_{S_{-} A}, v_{S_{-}} B$ and $v_{S_{-} C}$; (c) Currents of the power grid $i_{S_{-} A}, i_{S_{-} B}, i_{S_{-} C}$; (d) Currents of the railway system measured at the power grid side, $i_{\text {Rail_A }}, i_{\text {Rail_B }}, i_{\text {Rail_C }}$; (e) Ccompensation currents, $i_{\text {Comp_A }}, i_{\text {Comp_B }}, i_{\text {Comp_C }}$; (f) Voltage in the catenaries, $v_{x}$ and $v_{y}$; (g) Currents of catenaries, $i_{x}$ and $i_{y}$.

At the time instant of $\mathrm{t}=0.10 \mathrm{~s}$, there are two locomotives in the railway power system, 
one in the catenary $x$ and the other in the catenary $y$, consuming a current $i_{x}$ and $i_{y}$, respectively. These two currents are in phase with the respective voltages of the catenary side $v_{x}$ and $v_{y}$. Once again, $i_{\text {Rail } A}, i_{\text {Rail_B }}$ and $i_{\text {Rail } C}$ reflect the non-sinusoidal waveform of the catenary side currents, being $i_{x}$ in phase with $i_{\text {Rail }}$ A and $i_{y} 90^{\circ}$ lags the current $i_{x}$. However, it should be noted that, in this case, the currents on the power grid side have similar amplitudes, making the system more balanced.

At the time instant of $\mathrm{t}=0.16 \mathrm{~s}$, a railway system powered by Scott power transformer, another unbalance scenario was considered in the simulation, in which, catenary $x$ has one locomotive and catenary $y$ has two locomotives. At this moment, it can be verified that the waveforms of $i_{x}$ and $i_{y}$, as well as the currents $i_{\text {Rail } A}, i_{\text {Rail }} B$ and $i_{\text {Rail }} C$, are distorted. Considering the locomotives are equal and the catenary $y$ has double the load value of catenary $x$, it can be seen that $i_{y}$ has twice the amplitude of $i_{x}$. On other hand, $i_{\text {Rail_ } A}$ maintains its previous amplitude and $i_{\text {Rail } B}$ and $i_{\text {Rail_C }}$ increase 1.8 times.

At the moment that STATCOM is activated, at the time instant of $\mathrm{t}=0.04 \mathrm{~s}$, it is able to inject the harmonic contents and reactive power, required by the railway system, making $i_{S_{-} A}, i_{-} B$ and $i_{S_{-} C}$ sinusoidal and balanced. In fact, the railway system continues to consume a highly distorted current, $i_{\text {Rail } A}, i_{\text {Rail_B }}$ and $i_{\text {Rail } C}$, as can be seen in Fig. 5 (d). To highlight that, the STATCOM was able to dynamically overcome the PQ deterioration, independently of the load variations. At this moment, the biggest differences between this system and the system powered by the $\mathrm{V} / \mathrm{V}$ is when the railway system has a locomotive in each catenary. As an example, at the time instant between $\mathrm{t}=0.1 \mathrm{~s}$ and $\mathrm{t}=0.16 \mathrm{~s}$, where STATCOM only has to synthesize a compensation current with $10 \mathrm{~A}$ of peak, which represents $1 / 2$ of the value when the same system was to operate with the V/V power transformer. In general, it can be seen that the STATCOM needs to synthesize a much smaller compensation current when the railway system is powered by a Scott power transformer. Continuing with the analysis of the obtained result, it was verified that this system was able to reduce the THD $\%$ of the power grid currents, $i_{S_{-} A}, i_{-} B$ and $i_{S_{-} C}$, from the values exposed in Table 2.1 , to $2.99 \%, 2.75 \%$, $2.89 \%$ respectively. This represent an average reduction of $75 \%$ in terms of the THD.

\subsection{Evaluation Performance of the V/V and Scott Power Transformers}

In order to evaluate the performance of the STATCOM with different power transformers, the harmonic contents in the three-phase power grid were analyzed. For that purpose, it was only considered the scenario when both of the catenary load. That is, section $x$ and $y$ were equally loaded with one locomotive for each section, as represented in the instant between $\mathrm{t}=0.10 \mathrm{~s}$ and $\mathrm{t}=0.16 \mathrm{~s}$.

Initially and by considering a railway system powered by a V/V power transformer and without STATCOM, the harmonic spectrum of the $i_{S_{-} A}, i_{S_{-} B}$ and $i_{S_{-} C}$ is shown in Fig. 6 (a). At that case, the harmonic contents in $i_{S_{A} A}$ are similar to the ones of $i_{S_{B} B}$, being $i_{S_{-} C}$ with a higher amplitude. On the contrary, $i_{S_{-} C}$ has a lower value in the $3^{\text {rd }}, 9^{\text {th }}$ and $15^{\text {th }}$ harmonic contents. When a dynamic compensation is performed by the STATCOM, it is possible to see in Fig. 6 (b) that the APF was able to reduce the harmonic contents in $i_{S_{-} A}, i_{S_{-} B}$ and $i_{S_{-} C}$. On the other hand, the harmonic contents in $i_{x}$ and $i_{y}$ before (Fig. 6 (c)) and after (Fig. 6 (d)) compensation, does not show a difference. 

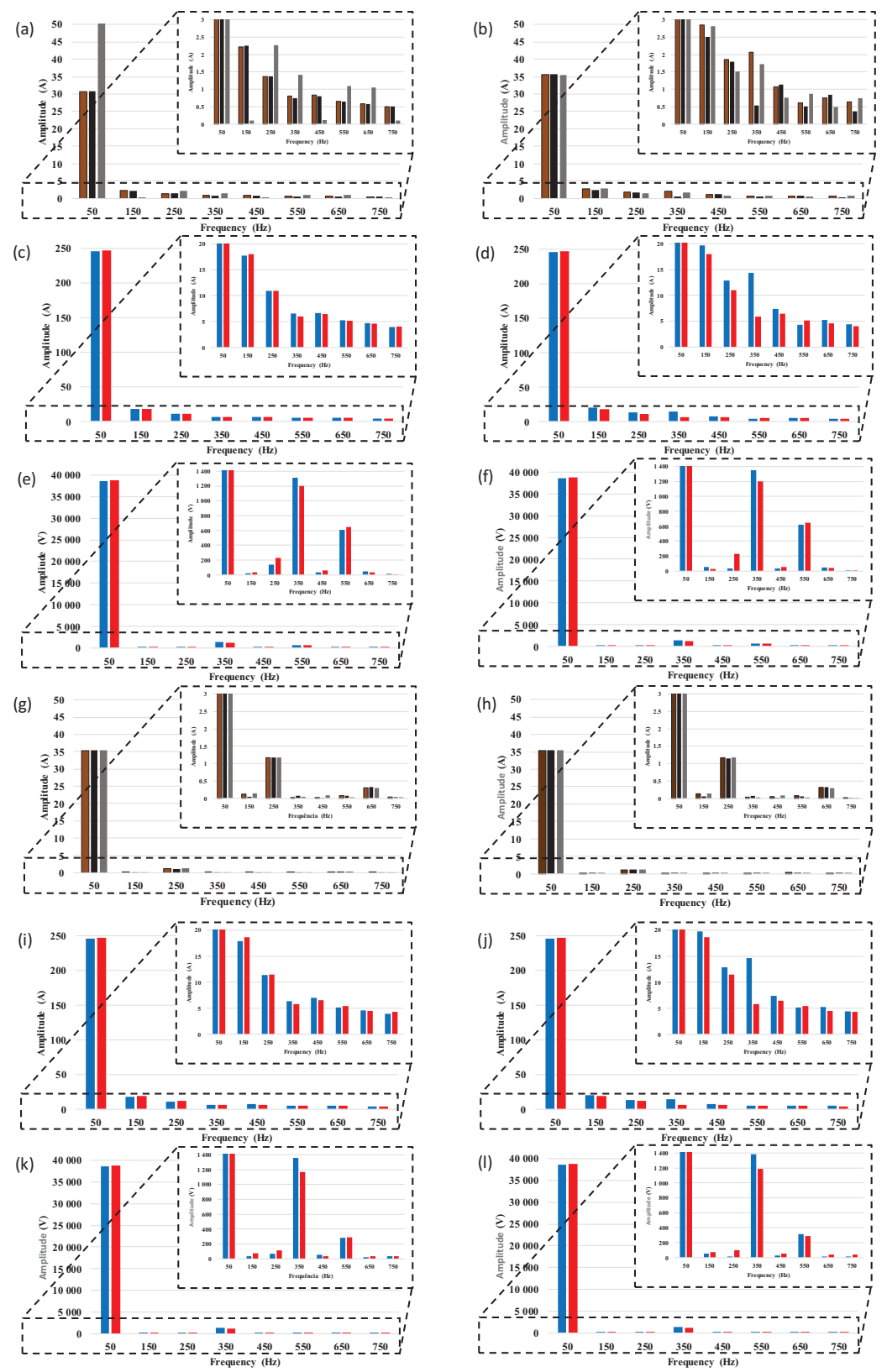

Fig. 6. Harmonic spectrum of the voltages and the currents in the three-phase power grid and in the catenary, before and after STATCOM compensation.

Considering now the railway power system is powered by a Scott power transformer, it is possible to see the harmonic spectrum of the $i_{S_{-} A}, i_{S_{-} B}$ and $i_{S_{-} C}$ presented in Fig. 6 (g). In this case, it can be verified that the harmonic contents of fundamental 
component is more uniform. When the STATCOM is activated, it is possible to reduce the remaining harmonic contents values, as can be seen in Fig. $\mathbf{6}$ (h). In a similar way to previous system, the harmonic content in $i_{x}$ and $i_{y}$ before (Fig. 6 (i)) and after (Fig. $6(j)$ ) compensation does not undergo any alteration in the railway system powered by a Scott.

In terms of voltage harmonics in the catenary, $v_{x}$ and $v_{y}$, both topologies have a similar performance, as can be seen in Fig. 6 (e) for the V/V power transformer and in Fig. 6 (k) for the Scott power transformer. The major difference is regarding the suppression of the $5^{\text {th }}$ order harmonic at the catenary section $x$ when using the Scott power transformer. However, a dynamic compensation of these PQ phenomena is still required. In this context, STATCOM provides a dynamic compensation that allows to reduce the harmonic distortions in the catenary voltages, as can be seen in Fig. 6 (f) for the railway power system powered by V/V power transformer and in Fig. 6 (I) for the railway power system powered by Scott power transformer. However, and since the STATCOM is upstream of the V/V and Scott power transformers, many of the harmonics created by the railway system are induced in the transformers. This causes them to overheat and increase energy losses.

\section{Conclusions}

This paper showed the importance of a Static Synchronous Compensator (STATCOM) in the electrified railway systems when using V/V or Scott power transformer. Simulation results of STATCOM for a dynamic compensation are presented. For this study it was considered different number of locomotives along the overhead catenary lines.

Results show that Scott power transformer is able to eliminate the $5^{\text {th }}$ harmonic order only in the catenary $x$, as well as presenting a system more balanced. In fact, the compensation currents of the STATCOM for a railway system powered by a Scott power transformer are much lower than in a system powered by the V/V power transformer. Then, the STATCOM power ratings is lower when using the Scott power transformer. On the other hand, results show that V/V power transformer has less capability to overcome unbalance and harmonic distortions in the three-phase power grid. However, it has a simple structure and lower costs than the Scott power transformer.

The results show that the STATCOM is capable not only to balance the currents in the three-phase power grid, but also to reduce the harmonic contents by $67 \%$ and by $75 \%$ for a railway system powered by a V/V and Scott power transformer, respectively.

\section{Acknowledgements}

This work has been supported by FCT - Fundação para a Ciência e Tecnologia within the Project Scope: UID/CEC/00319/2019. This work has been supported by the FCT Project QUALITY4POWER PTDC/EEI-EEE/28813/2017, and by the FCT Project DAIPESEV PTDC/EEI-EEE/30382/2017. Mr. Luis A. M. Barros is supported by the doctoral scholarship PD/BD/143006/2018 granted by the Portuguese FCT foundation. Mr. Mohamed Tanta was supported by FCT $\mathrm{PhD}$ grant with a reference $\mathrm{PD} / \mathrm{BD} / 127815 / 2016$. 


\section{References}

[1] M. Brenna, F. Foiadelli, and D. Zaninelli, Electrical railway transportation systems, vol. 67. John Wiley $\backslash \&$ Sons, 2018, ISBN: 978-1-119-38680-3.

[2] S. Frey, Railway electrification. White word publications,2012,ISBN:978-81-323-4395-0.

[3] N. Mazzino, X. Perez, N. Furio, and others, "Rail 2050 Vision: Rail-the Backbone of Europe's Mobility," ERRAC-The European Rail Research Advisory Council, Technical Report, 2017.

[4] R. Targosz and D. Chapman, "Application note-cost of poor power quality," Leonardo Energy, 2012.

[5] A. Luo, C. Wu, J. Shen, Z. Shuai, and F. Ma, "Railway static power conditioners for highspeed train traction power supply systems using three-phase V/V transformers," IEEE Transactions on Power Electronics, vol. 26, no. 10, pp. 2844-2856, 2011, doi: 10.1109/TPEL.2011.2128888.

[6] M. Tanta, V. Monteiro, T. J. Sousa, A. P. Martins, A. S. Carvalho, and J. L. Afonso, "Power quality phenomena in electrified railways: Conventional and new trends in power quality improvement toward public power systems," in Young Engineers Forum (YEF-ECE), 2018 International, 2018, pp. 25-30, doi: 10.1109/YEF-ECE.2018.8368934.

[7] K.-W. Lao, M.-C. Wong, and N. Dai, Co-phase Traction Power Supply with Railway Hybrid Power Quality Conditioner. Springer, 2019, doi: 10.1007/978-981-13-0438-5, ISBN: 978-981-13-0438-5.

[8] K.-W. Lao, M.-C. Wong, N. Dai, C.-S. Lam, L. Wang, and C.-K. Wong, “Analysis of the Effects of Operation Voltage Range in Flexible DC Control on Railway HPQC Compensation Capability in High-Speed Co-phase Railway Power," IEEE Transactions on Power Electronics, vol. 33, no. 2, pp. 1760-1774, 2018, doi: 10.1109/TPEL.2017.2684427.

[9] A. Steimel, Electric Traction - Motive Power and Energy Supply: Basics and Practical Experience. Oldenbourg Industrieverlag, 2008, ISBN: 978-3-8356-3132-8.

[10] S. M. M. Gazafrudi, A. T. Langerudy, E. F. Fuchs, and K. Al-Haddad, "Power quality issues in railway electrification: A comprehensive perspective," IEEE transactions on industrial electronics, vol. 62, no. 5, pp. 3081-3090, 2015, doi: 10.1109/TIE.2014.2386794.

[11] L. Abrahamsson, T. Schütte, and S. Östlund, "Use of converters for feeding of AC railways for all frequencies," Energy for Sustainable Development, vol. 16, no. 3, pp. 368-378, 2012, doi: 10.1016/j.esd.2012.05.003.

[12] K. Lee, "Advances in the application of power electronics to railway traction," in Power Electronics Systems and Applications (PESA), 2015 6th International Conference on, 2015, pp. 1-4, doi: 10.1109/PESA.2015.7398960.

[13] D. Serrano-Jiménez, L. Abrahamsson, S. Castaño-Solis, and J. Sanz-Feito, "Electrical railway power supply systems: Current situation and future trends," International Journal of Electrical Power I\& Energy Systems, vol. 92, pp. 181-192, 2017, doi: 10.1016/j.ijepes.2017.05.008.

[14] Q. Xu, F. Ma, Z. He, Y. Chen, J. M. Guerrero, A. Luo, Y. Li, and Y. Yue, "Analysis and comparison of modular railway power conditioner for high-speed railway traction system," IEEE Trans. Power Electron., vol. 32, no. 8, pp. 6031-6048, 2017, doi: 10.1109/TPEL.2016.2616721.

[15] F. Ma, Q. Xu, Z. He, C. Tu, Z. Shuai, A. Luo, and Y. Li, “A railway traction power conditioner using modular multilevel converter and its control strategy for high-speed railway system," IEEE Transactions on Transportation Electrification, vol. 2, no. 1, pp. 96-109, 2016, doi: 10.1109/TTE.2016.2515164.

[16] J. Pinto, M. Tanta, V. D. F. Monteiro, L. A. Barros, and J. L. Afonso, “Active power conditioner based on a voltage source converter for harmonics and negative sequence components compensation in electrified railway systems," in Proceedings of 7th Transport Research Arena TRA 2018, 2018, doi: 10.5281/zenodo.1491309. 